\title{
Bio impresión 3D: importancia en la actualidad
}

\author{
Bio 3D printing: importance today
}

Bio 3D printing: importance todayumbilical

\section{ARTÍCULO GENERAL}

\section{César Loo Gil \\ cesarloo@biofab.com.pe \\ https://orcid.org/0000-0001-8396-5972}

Científico Investigador de BioFab Inc, y del Centro de Investigación \& Producción Científica IDEOs, Lima - Perú

Recibido 08 de Agosto 2020 | Arbitrado y aceptado 28 de Setiembre 2020 | Publicado en 05 Marzo 2021

\section{RESUMEN}

El trasplante de órganos y tejidos para ofrecer solución a heridas y deficiencias es un inconveniente que con urgencia se debería intentar, puesto que todavía hay problemas en el proceso, como la escasez de donantes y el peligro que provoca el rechazo inmunológico. La implementación de órganos y tejidos artificiales indica una mejor calidad de vida en los pacientes, no obstante, es necesario de una técnica de manufactura que posibilite el desarrollo de construcciones complicadas. La técnica de impresión 3D da solucionar las restricciones recientes en el desarrollo de órganos y tejidos, debido a que posibilita integrar células en los biomateriales para la regeneración de distintas construcciones biológicas. Esta revisión resume los estudios más importantes y el avance en el desarrollo de implantes, prótesis e ingeniería de tejidos por medio de impresión $3 \mathrm{D}$, se introduce a los diversos biomateriales empleados en la manufactura aditiva, así como las múltiples técnicas de impresión usadas en aplicaciones biomédicas.

Palabras clave: impresión 3D; dispositivos médicos; biomateriales

\section{ABSTRACT}

The transplantation of organs and tissues to offer a solution to wounds and deficiencies is an issue that should be urgently attempted, since there are still problems in the process, such as the shortage of donors and the danger caused by immunological rejection. The implementation of artificial organs and tissues indicates a better quality of life for patients, however, a manufacturing technique is needed to enable the development of complicated constructions. The 3D printing technique provides a solution to recent restrictions in the development of organs and tissues, since it makes it possible to integrate cells into biomaterials for the regeneration of different biological constructions. This review summarizes the most important studies and progress in the development of implants, prostheses and tissue engineering by means of $3 \mathrm{D}$ printing, introduces the various biomaterials used in additive manufacturing, as well as the multiple printing techniques used in biomedical applications.

Keywords: 3D printing; medical devices; biomaterials

\section{RESUMO}

O transplante de órgãos e tecidos para solucionar feridas e deficiências é um incômodo que deve ser tentado com urgência, uma vez que ainda existem problemas no processo, como a escassez de doadores e o perigo da rejeição imunológica. A implantação de órgãos e tecidos artificiais indica uma melhor qualidade de vida aos pacientes, porém, é necessária uma técnica de fabricação que permita o desenvolvimento de construções complicadas. A técnica de impressão 3D resolve as recentes restrições no desenvolvimento de órgãos e tecidos, pois permite a integração de células em biomateriais para a regeneração de diferentes construções biológicas. Esta revisão resume os estudos e avanços mais importantes no desenvolvimento de implantes, próteses e engenharia de tecidos por meio de impressão $3 \mathrm{D}$, apresenta os diversos biomateriais utilizados na manufatura aditiva, bem como as múltiplas técnicas de impressão utilizadas em aplicações biomédicas.

Palavras-chave: impressão 3D; dispositivos médicos; biomateriais 


\section{INTRODUCCION}

Las tecnologías de salud son primordiales para un sistema de salud en adecuado manejo. Especialmente, los dispositivos doctores son cruciales en la prevención, diagnóstico y procedimiento de patologías, así como en la rehabilitación de pacientes. La demanda mundial de dispositivos doctores experimenta un aumento constante en los últimos años impulsada por el envejecimiento poblacional y el progreso tecnológico. Esta tendencia está significando adelantos relevantes en el desarrollo de las biotintas y en la optimización de las técnicas de deposición de estas.

Las biotintas se elaboran con una extensa gama de materiales. Los dispositivos doctores tienen la posibilidad de agruparse en 2 gigantes conjuntos: a) esos en que para su preparación prescinden de células, ejemplificando, las prótesis o órtesis y b) esos cuya preparación necesita que se agreguen células. Generalmente, para la preparación de un dispositivo doctor, las biotintas tienen que exponer ciertas características como la función de procesarse a temperatura ambiente, que se logre imprimir rebordes y tener un cierto nivel del control de la microestructura. En la literatura se hallan revisiones acerca del estado de la técnica de preparación y procesamiento de biotintas en los cuales se destaca la información relacionada con la ingeniería de tejidos y medicina regenerativa. Generalmente, las biotintas están basadas en materiales poliméricos naturales y sintéticos; sin embargo, Poologasundarampillai y Nommeots-Nomm en 2017 presentaron una discusión de los materiales impresos en 3D con los que se elaboran implantes para reparación y regeneración de tejidos en los que se incluían metales y cerámicos, además de los polímeros. Por un lado, los materiales cerámicos, como el fosfato de calcio, se imprimen a través del procesamiento de polvos, incluida la impresión por Fusión Selectiva por Láser (selective laser melting, SLM) presentan 
complicaciones derivadas de la química del aglutinante. Por otro lado, los metales y sus aleaciones, que tradicionalmente son usados para la elaboración de los dispositivos médicos como las $\mathrm{Ti}_{6} \mathrm{Al}_{4} \mathrm{~V}$, acero inoxidable $316 \mathrm{~L}$, aleación $\mathrm{CoCr}$, ven limitado su uso para impresión por 3D, debido a que las técnicas de procesamiento incluyen fusión de haz de electrones (electron beam melting, EBM) además de SLM, las cuales emplean equipos sofisticados y costosos. Los autores indicaron que los materiales derivados de magnesio y hierro son candidatos potenciales para elaborar dispositivos médicos implantables a partir de metales, ya que estos materiales están diseñados para controlar la velocidad de su degradación; sin embargo, la bioacumulación y la consiguiente toxicidad de los productos de la degradación y la nueva interfaz formada después de la degradación aún deben investigarse a fondo. Por lo anterior, el presente trabajo de revisión está enfocado en los dispositivos médicos basados en materiales poliméricos. De este modo, Gopinathan y Noh analizaron los reportes de biotintas basadas en polímeros utilizadas en la impresión 3D para aplicaciones en ingeniería de tejidos y medicina regenerativa. Los autores enlistaron varios trabajos recientes en los que se emplean biotintas elaboradas a partir de materiales poliméricos naturales (agarosa, alginato, colágeno, ácido hialurónico, fibrina, celulosa, seda, matriz extracelular) y polímeros sintéticos y establecieron que la ingeniería de tejidos y medicina regenerativa, en particular, necesitan un gran número de células específicas, lo que limita su uso en diferentes tejidos y órganos. Mientras que el estado del arte de las propiedades de los biomateriales poliméricos empleados como biotintas analizado por Mukherjee y col. (2019) los llevó a deducir que la semejanza de los polímeros naturales con la matriz extracelular es alta, por lo que producen una adecuada bioactividad; mientras que los polímeros sintéticos aumentan la integridad mecánica en la bioimpresión y eliminan las limitaciones de fabricación. Por otro lado, la revisión de Ashammakhi y col. (2019) destaca avances importantes la elaboración de biotintas heterogéneas para fabricar 
construcciones de tejido biomimético. Estos autores han determinado que es importante desarrollar biotintas con la propiedad de reducción de la viscosidad aparente con una tasa de cizallamiento creciente y que además posea características biológicas deseadas para diferentes aplicaciones de ingeniería de tejidos. Ya que, desafortunadamente, la mayoría de los hidrogeles que se han utilizado para la bioimpresión 3D se degradan en 3 semanas. Según Martins y col., el abordaje de este problema incluye el uso de fibras de refuerzo o nanopartículas ya que aseguran que los andamios 3D nanoestructurados imitan los entornos biológicos, con propiedades fisicoquímicas mejoradas. Además, que son capaces de funcionalizarse para una mejor respuesta celular.

Los avances en imagenología médica y software de diseño 3D han proporcionado una oportunidad sin precedentes para la atención al paciente mediante la impresión de dispositivos médicos. La impresión 3D se basa en el principio de la fabricación en capas, es decir, los materiales se superponen capa por capa hasta formar el modelo deseado. Mediante esta tecnología se puede fabricar cualquier estructura compleja con ayuda de un diseño asistido por computadora (CAD) o tomografía computarizada (TC). Los métodos convencionales de trabajo con máquinas y de fundición difícilmente crean una estructura tridimensional con forma compleja, con porosidad controlada, distribución controlada de tamaño de poros y de estructura inclinada; lo que sí es posible obtener mediante impresión 3D. Además de la precisión de impresión, la tecnología 3D ofrece velocidad y costos de 


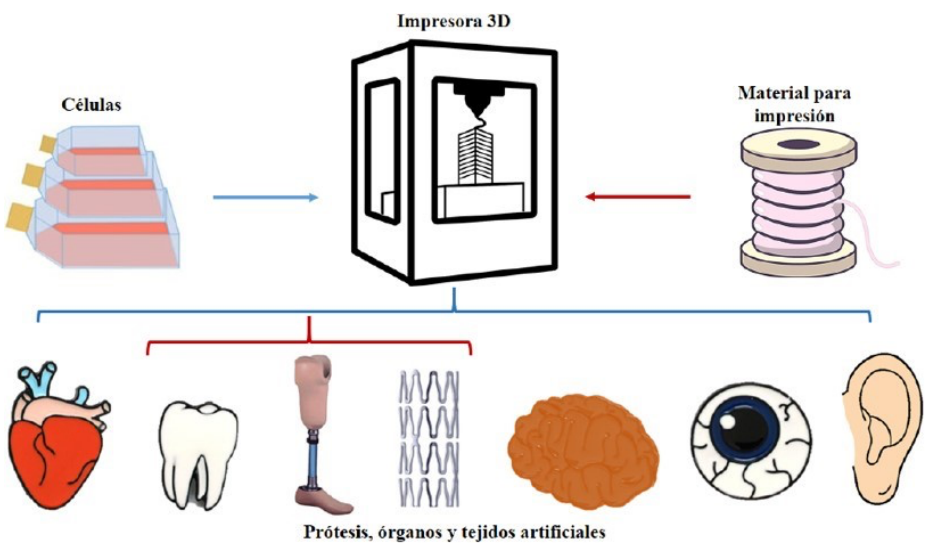

fabricación reducidos, lo cual

permite grandes avances en una gran variedad de dispositivos médicos (figura 1).

Figura 2 Esquema general de bioimpresión 3D, (-) aplicaciones que pueden o no llevar células.

Por ello, este proceso representa la manera más novedosa de fabricación de dispositivos médicos. En la literatura se encuentran varios trabajos de revisión acerca de las técnicas de impresión 3D (figura 2), también conocida como manufactura aditiva, para desarrollar dispositivos biomédicos en las que predomina el enfoque hacia la ingeniería de tejidos. La impresión 3D o fabricación aditiva de dispositivos médicos es cada vez más común y la tecnología está transitando del laboratorio al mercado, según lo presentado por Di Prima y col. en la revisión de la perspectiva de las entidades regulatorias acerca del avance de esta tecnología médica que no está exenta de las regulaciones y consideraciones técnicas aplicables. 


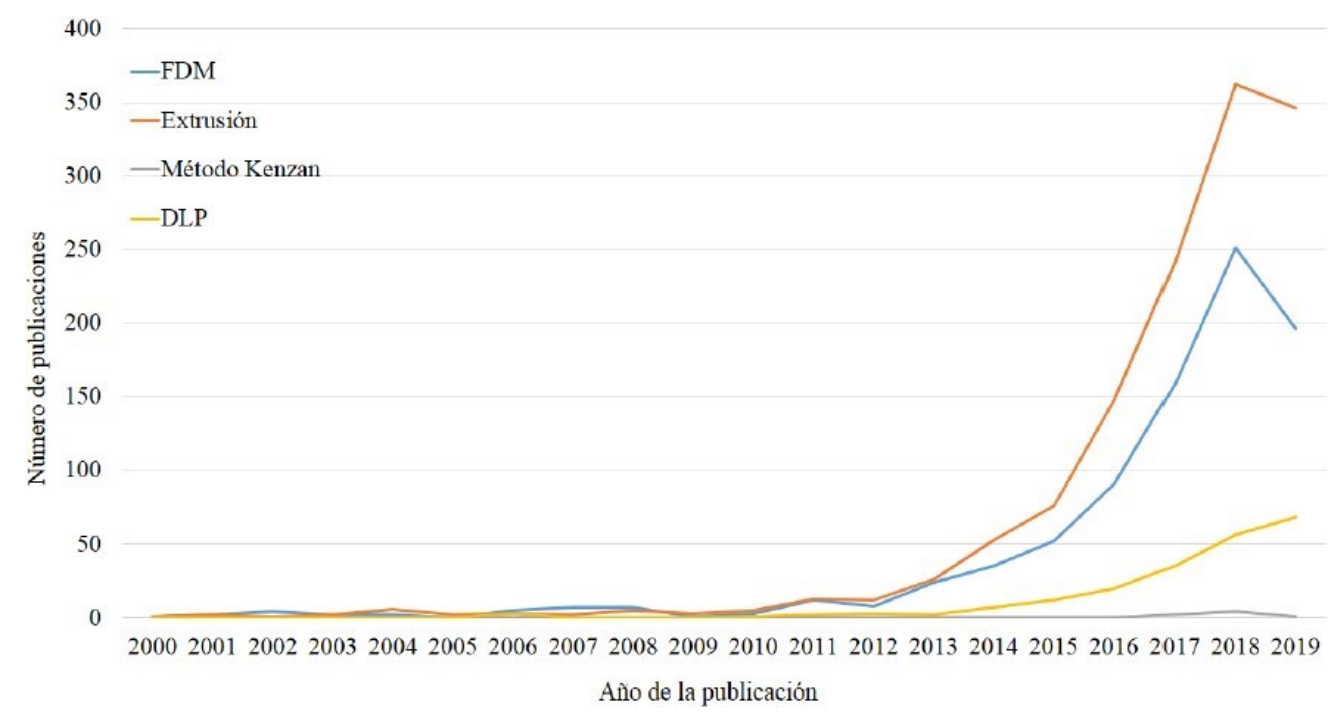

Figura 3 Gráfico de tendencia de diversas técnicas de impresión 3D empleadas con frecuencia en aplicaciones biomédicas.

\section{METODOLOGÍA}

La metodología utilizada consta de búsqueda de información de paper, revistas, análisis de aplicaciones actuales y páginas web especializadas para entender su funcionamiento, el nivel de desarrollo obtenido en la actualidad y cuáles son sus principales aplicaciones. Además, se emplean análisis de modelos estratégicos acordes para analizar el atractivo de las industrias en la adopción de la tecnología y así determinar a través de modelos de análisis de negocio cuáles son las industrias en que tendrá mayor incidencia.

La búsqueda de la información para la revisión de literatura se hizo consultando las siguientes bases de datos como son Proquest, Scopus y Google Scholar para encontrar revistas del más alto nivel científico. Asimismo, cabe mencionar que para la realización de lo mencionado se emplearon también palabras clave como como Computación en la nube, Contrato de servicios, Privacidad, ser humano.

Cada uno de estos descriptores se combinaron entre sí durante la búsqueda utilizando los operadores boléanos "and” y "or". Además, algunos de los criterios o filtros que se utilizaron para hacer muchos más específica la búsqueda y ser más precisos con los 
documentos encontrados en las diferentes bases de datos consultadas fueron: que sean artículos de revistas, y la antigüedad de la publicación que no sea mayor a 5 años. Toda la información previa relacionada a los filtros aplicados y las especificaciones sirvieron como criterios de inclusión, es decir que sean artículos publicados en revistas científicas, que no excedan los cinco años de antigüedad, que la temática guarde relación con las variables de creatividad artística y tiempos de pandemia. Se excluyeron, en tanto, todos los documentos que no respetaran lo postulado así como aquellos que estaban incompletos o que tenían enlaces averiados.

\section{RESULTADOS Y DISCUSION}

\subsection{Impresión 3D}

\subsubsection{Nociones básicas}

La impresión 3D (término introducido a la terminología MeSH en 2015) se define como "un conjunto de procesos usados para realizar un objeto físico tridimensional, también conocido como «prototi- pado rápido»". Esto se realiza mediante la aplicación capa por capa de un material sólido a temperatura ambiente, con un punto de fusión conocido con- trolado por un sistema computarizado para crear dicho objeto.

Esta técnica fue desarrollada originalmente para imprimir capas secuenciales finas de material, seguido de un proceso de curado con luz ultravioleta para formar sólidas estructuras tridimensionales al que se denominó “estereolitografía”, descrita por primera vez en 1986 por Charles W. Hull. Con el transcurso de los años, esta técnica ha evolucionado a pasos agigantados y se ha logrado volverla más rápida y compleja. La elaboración de objetos mediante impresión 3D se realiza a partir de un archivo cuya base estructural es un modelo tridimensional virtual viable, en el caso de su aplicación en medicina, son requeridos los estudios de imagen de un paciente para crear un molde a la medida. Un modelo no es sino la representación digital de lo que se planea imprimir mediante algún programa computarizado para modelarlo. 
En la actualidad existe una amplia variedad de programas de cómputo especializados, útiles en este proceso principalmente los de tipo CAD (computeraided design o diseño asistido por computadora) y los de tipo CAM (computeraided manufacturing o fabricación asistida por computadora) de uso extendido en el área de las ingenierías, ejecutables y modificables en diversas plataformas como BLENDER $₫$ y AutoCAD $\AA$, los archivos resultantes son utilizados como base en el diseño de diversos objetos compatibles con la impresión en tercera dimensión.

Desde que fue posible combinar impresión 3D con la tecnología tipo CAD/CAM, se ha intentado fabricar estructuras tridimensionales biomiméticas (con imitación anatomofuncional de un tejido) únicas del tejido u órgano que se desea replicar, utilizando las imágenes médicas de los pacientes para intentar preservar al máximo su anatomía. La resonancia magnética nuclear $(\mathrm{RMN})$, la tomografía axial computarizada (TAC) y otras imágenes radiográficas son las principales fuentes para obtener información volumétrica tridimensional de tejidos y órganos. La información obtenida mediante estos recursos se almacenan en un archivo de imágenes digitales (archivo .DICOM, por sus siglas en inglés) que después se utilizan para desarrollar el modelo CAD mediante un proceso de ingeniería inversa. Así, este proceso transforma la "anatomía analítica" en "anatomía sintética".

Este tipo de archivos son, por definición, un constructo tridimensional, virtual e intangible. Actualmente la impresión 3D es una herramienta que nos permite, mediante un programa de impresión especial, construir un modelo a partir de lo virtual a lo tangible. Para esto es necesario convertir el diseño o modelo a un formato o "idioma" conocido por la impresora con un archivo de extensión STL (Stereolitography). A partir de este formato, la im- presora ejecuta los comandos para la construcción de cualquier modelo, en coordenadas milimétricas englobadas en el espacio de impresión conforme a los ejes 
$\mathrm{X}, \mathrm{Y}$ y Z (figura 2)

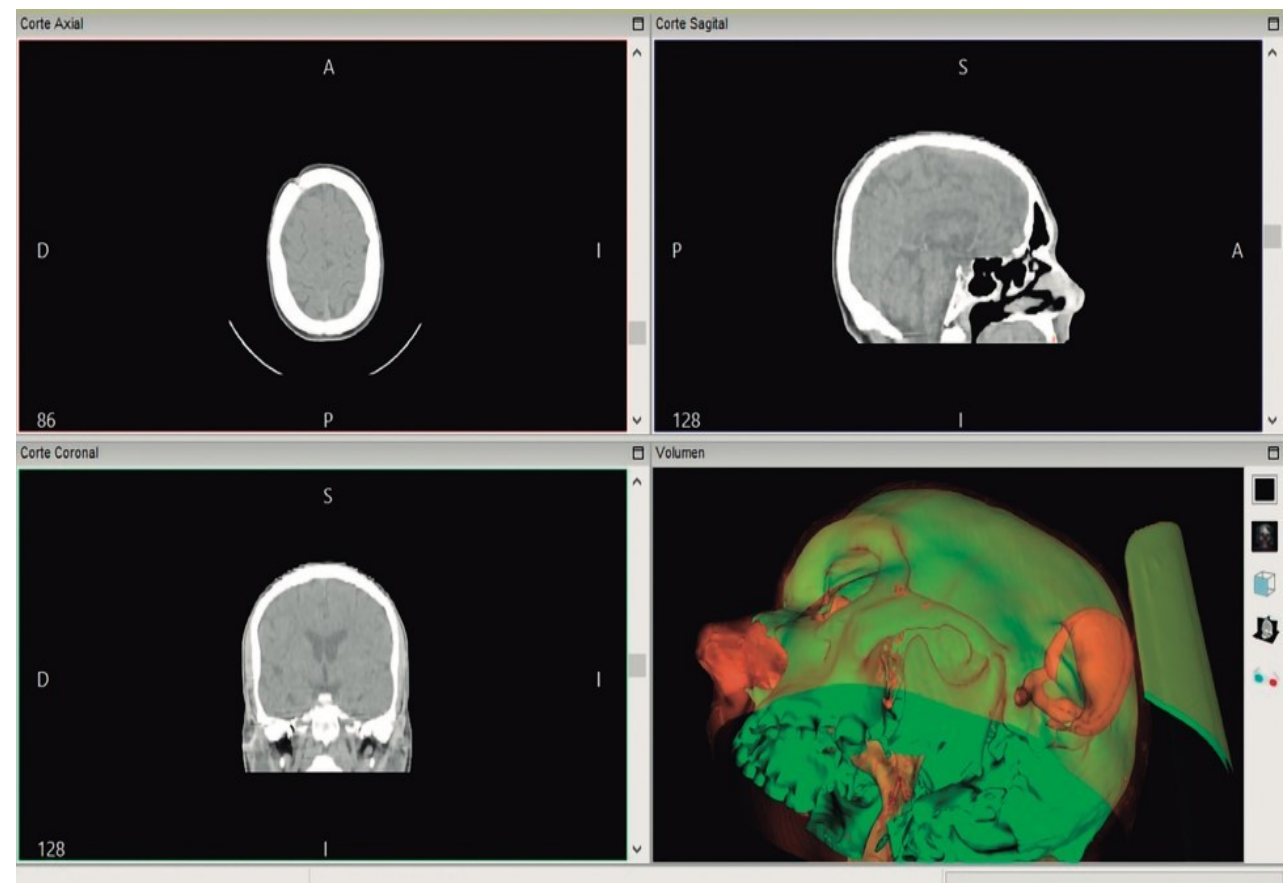

Figura 1. Ejemplo de reconstrucción a partir de una TC de cráneo con cortes sagitales, coronales y axiales en

Invesalius $\subset$ versión 3.1 que es un software libre de ingeniería reversa que utiliza una secuencia de archivos 2D tipo DICOM para generar volúmenes o superficies como archivos de mallas para crear modelos físicos de la anatomía del paciente utilizando TFA. InVesalius fue desarrollado en CTI (Centro de Tecnología de la Información Renato Ar- cher) en 2007, un instituto de investigación del Centro de Ciencia y Tecnología de Brasil y está disponible sin costo en la página de inicio del Portal de Software Público. La licencia del software es CC-GPL 2.

La impresora 3D consiste esencialmente de un brazo robótico multieje o mejor conocido como robot cartesiano (con 3 ejes $\mathrm{X}, \mathrm{Y}, \mathrm{Z}$ ) con una boquilla extrusora, una fuente de energía, y un sustrato para depositar el material fundido5. 
En la mayoría de los casos de impresión 3D se utilizan materiales termoplásticos, que como su nombre lo indica, adquieren la forma semilíquida a temperaturas mayores a los 120 oC, convirtiéndo- lo en un material fácilmente aplicable mediante la boquilla extrusora que va depositando finas capas sobre una plataforma hasta la construcción del mo- delo, que se endurece a medida que la temperatura del material disminuye. Esta técnica permite utili- zar materiales termoplásticos como el PLA (ácido poliláctico), ABS (acrilonitrilo butadieno estireno), HDPE (polietileno de alta densidad), metales sinté- ticos, e inclusive materiales comestibles o fármacos.

\subsubsection{Aplicaciones de los modelos 3D en medicina}

Hasta la fecha existen más de 80 artículos indizados en PUBMED que indican las distintas aplicaciones médicas de las impresiones 3D en la medicina, las cuales pueden agruparse de forma general en 3 categorías:

\section{Modelos anatómicos}

Los modelos 3D pueden emplearse con fines educativos, tanto para pacientes como para estudiantes, médicos en adiestramiento y cirujanos, y pueden jugar un papel importante en el proceso de reconstrucción de casos quirúrgicos complejos. Estos modelos asisten al cirujano en demostrar la complejidad de los casos al paciente y a sus familiares, también son excelentes auxiliares para entender la naturaleza del procedimiento por médicos en entrenamiento y especialistas.

Planeación preoperatoria

La impresión 3D se ha introducido recientemente en el campo quirúrgico como una herramienta para una mejor comprensión de cualquier anomalía subyacente compleja. Esto puede mejorar y facilitar la calidad diagnóstica y ayudar en la planificación 
prequirúrgica. Se ha demostrado su aplicación y be- neficio en la cirugía craneofacial y maxilofacial. Los primeros estudios en cirugía ortopédica, neu- rocirugía, cirugía de columna, cirugía cardiovascu- lar y cirugía abdominal, demostraron una mejora significativa en el diagnóstico y tratamiento debido a una mejor apreciación de la estructura afecta- da, mayor precisión y posibilidad de una adecuada planificación previa13-18. Simular todos los pasos quirúrgicos complicados por adelantado usando modelos prototipo puede ayudar a prever complicaciones intra y postoperatorias. Esto puede resultar en una reducción del tiempo cirugía que permite un uso rentable de las salas19,20. El empleo de placas en las fracturas articulares complejas, como las de acetábulo, osteotomías en displasia del desarrollo de la cadera u osteotomías de alineación, son un claro ejemplo de su utilización dado que permite la planeación del premoldeado de las placas de osteosíntesis -incluso antes de esterilizarlas-, la selección del implante ideal de acuerdo con sus dimensiones, la longitud de los tornillos, la direccionalización y sitios de cuidado en su manejo.

Investigación médica

La impresión 3D abre nuevas oportunidades para las actividades de investigación científica, pudiendo ayudar a elucidar los procesos fisiológicos que aún no se entienden completamente. La hemodinámica puede ser investigada, por ejemplo, mediante RM de velocidad codificada o por mediciones de flujo óptico en modelos transparentes.

\subsubsection{Implantes}

Si bien la función de un implante es restablecer el funcionamiento de alguna estructura biológica, actualmente también permite mejorar la estética gracias a la técnica de impresión 3D. Puesto que dicha técnica no sólo permite adaptar el implante a las 
necesidades del paciente, sino que lo vuelve único al desarrollarlo según las condiciones anatómicas de quien lo requiere. Lo anterior se torna sumamente importante en los implantes donde los resultados estéticos son notables, tal es el caso de los implantes craneofaciales.

Implantes craneofaciales

Los implantes craneofaciales han evolucionado de manera acelerada en los últimos años, pues a través la impresión 3D se han desarrollado implantes hechos a la medida, permitiendo el tratamiento de secuelas de la extirpación tumoral y la pérdida de tejido óseo.

En al año 2017, Abdullah y col. evaluaron las propiedades físicas y mecánicas de la poliamida 12 con zirconia y $\beta$-Fosfato tricálcico ( $\beta$-TCP), para su aplicación en reconstrucción craneofacial mediante impresión 3D. La poliamida 12 presenta gran tenacidad, mientras que el $\beta$-TCP mejora la adhesión celular y la proliferación debido a su similitud con el hueso humano. El implante craneofacial depende de la condición anatómica del paciente, además debe contar con características mecánicas adecuadas y una superficie que permita la adhesión celular, la manufactura aditiva permite obtener dichas condiciones en el implante.

Implantes cardíacos

En la actualidad, los defectos cardíacos sean congénitos o no, representan un grave problema para la sociedad. Puesto que el mal funcionamiento de las válvulas cardíacas, las paredes del corazón o las venas y arterias que irrigan a dicho órgano, puede provocar la interrupción total del flujo sanguíneo. Por tal motivo, en el año 2018, Faletti y col., obtienen un anillo aórtico mediante impresión 3D a partir de imágenes de tomografía computarizada cardiovascular para el remplazo valvular aórtico. Los anillos aórticos se fabricaron mediante la técnica de deposición fundida de filamentos de poliuretano (PU). El diámetro del anillo aórtico medido en los modelos 3D mostró una concordancia 
adecuada con la medición de los anillos de la tomografía computarizada cardiovascular.

La impresión 3D de anillos aórticos mediante tomografía computarizada cardiovascular, ofrece información confiable y específica para cada caso clínico. Un año más tarde, Sun y col., fabrican un oclusor biodegradable para defectos cardiacos mediante la técnica de impresión tridimensional, con la finalidad de evaluar su bioseguridad en un modelo animal. Se empleó como biomaterial el copolímero PLLA-TMC-GA, permitiendo una adecuada impresión de oclusores biodegradables para defectos cardiacos con una biocompatibilidad adecuada.

Implantes de rodilla

Puesto que la rodilla es la articulación más vulnerable del cuerpo humano, es necesario el desarrollo de implantes que permitan restaurar su adecuado funcionamiento, es decir, su movilidad sin padecer dolor. Sin embargo, uno de los principales inconvenientes en el desarrollo de implantes de rodilla es la susceptibilidad del material al desgaste. Por tal motivo, con frecuencia son usados diversos compuestos poliméricos para la fabricación de implantes de rodilla mediante manufactura aditiva. En el año 2018, Borges y col. emplean una mezcla polimérica de policarbonato de uretano poroso (PCU) y polietileno de ultra alto peso molecular (UHMWPE) para la fabricación de menisco artificial de rodilla. Se encontró que es factible fabricar meniscos artificiales basados en PCU/UHMWPE mediante impresión 3D.

Implantes dentales

La técnica de impresión 3D también es empleada en el desarrollo de implantes dentales, tal es el caso de Yan y col., que en el año 2019 desarrollan nuevos rellenos dentales personalizados con acción terapéutica prolongada utilizando la impresión 3D, esto debido a la alta incidencia de la caries dental. Se obtuvieron moldes molares de PLA o ABS mediante escaneo 3D, los rellenos dentales de Tinidazol (TNZ) fueron fabricados por prensado térmico utilizando los moldes personalizados impresos en 3D. Los 
rellenos dentales desarrollados fueron capaces de liberar Tinidazol durante una semana.

La manufactura aditiva se puede emplear para fabricar rellenos dentales con alta resistencia mecánica y liberación de fármacos personalizada. Además de contar con un bajo costo y con una gran variedad de materiales para la impresión 3D.

\subsubsection{Prótesis}

La impresión 3D promete transformar la forma convencional en que las prótesis son desarrolladas, ya que posee un gran potencial de personalización, bajo costo y una rápida fabricación. Esta técnica de manufactura permite el desarrollo de prótesis de miembros superiores e inferiores con una adaptación adecuada a la anatomía de cada paciente, prótesis con capacidad de liberar fármacos e incluso prótesis con una estructura compleja como son las endoprótesis tubulares, es decir, los stents.

Prótesis de miembros superiores e inferiores

El objetivo de una prótesis es suplir la forma anatómica del miembro superior o inferior, así como facilitar la movilidad del paciente. Dicho objetivo es fácil de lograr con la técnica de impresión 3D, pues permite que la prótesis se adapte a cada caso clínico. En el año 2018, Alvial y col., evalúan el rendimiento de dos prótesis de silicona impresas mediante la tecnología de impresión 3D de un paciente con amputación parcial de la mano no dominante. Se tomaron moldes de alginato y tomografías computarizadas de la mano del paciente, luego, cada prótesis candidata se modeló y posteriormente se fabricó utilizando una combinación de piezas de silicona impresas en 3D. Se demostró que la fabricación de prótesis impresas en 3D es una buena técnica para mejorar el tratamiento clínico de pacientes con amputaciones parciales de la mano. Colombo y col. reportaron la aplicación de un entorno asistido por computadora, llamado Socket Modelling Assistant 2 (SMA2), en un paciente transfemoral, el cual consiste en la implementación de un conjunto de reglas de diseño extrapoladas del proceso de desarrollo tradicional de prótesis. Esto hace que el proceso de diseño sea más confiable y repetible y, al mismo 
tiempo, lo suficientemente parecido al proceso tradicional para ser aceptado por los protésicos.

Prótesis orbitales

Si bien, el desarrollo de prótesis de miembros inferiores y superiores mediante la tecnología de impresión 3D ha experimentado un gran auge en los últimos años, Kim y col. en el año 2019 apuestan por las prótesis orbitales personalizadas a través de la impresión tridimensional. La extirpación quirúrgica del contenido ocular y orbital es inevitable en casos como tumores orbitales malignos u oftalmía simpática, este último caso se trata de la inflamación del conducto uveal que se produce en un ojo después de una lesión o cirugía en el otro ojo. Por tal motivo, se utiliza una prótesis orbital para reconstruir las características faciales de los pacientes cuya órbita se ha eliminado parcial o totalmente. En dicho estudio se desarrolló un proceso personalizado para la fabricación de prótesis orbitales mediante diseño asistido por computadora (CAD) y la tecnología de impresión 3D. Se diseñó un molde para ser impreso en 3D con una resina biocompatible, la prótesis orbital se fabricó inyectando material de silicona también biocompatible en la cavidad del molde, cabe mencionar, que los datos del rostro del paciente fueron escaneados mediante un escáner portátil. Este método remplaza la mayoría de los pasos del proceso convencional por un proceso rápido, preciso y además no daña el tejido del paciente, ya que los métodos de fabricación tradicionales emplean alginato para crear la impresión, causado molestias en el paciente.

Stents

El tratamiento adecuado a la oclusión arterial es un problema contemporáneo. Puesto que los stents establecidos incluyen stents metálicos y stents liberadores de fármacos, sin embargo, las endoprótesis tubulares cargadas directamente con el fármaco pueden causar una liberación no controlada del mismo, además, de provocar reestenosis debido al andamio metálico del stent. Por tal razón, un stent ideal tendría la capacidad de 
reducir la reestenosis, degradarse completamente con el tiempo, ser un fuerte soporte vascular y mantener la liberación de un medicamento durante el proceso de curación vascular. Debido a las necesidades en la fabricación de stents anteriormente mencionas, en el año 2015 Park y col. desarrollan un stent capaz de liberar fármacos de forma controlada, basado en materiales biocompatibles y biodegradables utilizando un sistema de impresión 3D. El andamio del stent fue de policaprolactona (PCL) y fue recubierto con el fármaco sirolimus mezclado con polilactida-co-glicolido (PLGA) y polietilenglicol (PEG). El stent biodegradable y liberador de fármacos fue analizado y probado in vivo, y demostró ser efectivo en experimentos con animales. Los resultados indicaron que la cinética de liberación del fármaco sirolimos con el que fue recubierto el stent, mostró un perfil de liberación sostenida. Además, los resultados sugieren que el stent desarrollado es útil para tratar la trombosis y puede ser un andamio prometedor. De igual manera, se demostró que la técnica de impresión 3D produce con éxito stents de estructura compleja y podría utilizarse para la fabricación de stents liberadores de fármaco.

El interés por el desarrollo de stents poliméricos ha experimentado un crecimiento exponencial, pues cada vez más personas con obstrucción de arterias requieren stents en sus vasos sanguíneos. Los stents comerciales presentan diversos inconvenientes, por ejemplo, el stent de andamio metálico insertado en el organismo humano no se puede extraer, lo cual provoca reestenosis, además, causa dificultades en algunas inspecciones médicas, como en la obtención de imágenes por resonancia magnética. Por tal motivo, se busca utilizar diversos materiales poliméricos biodegradables en el desarrollo de stents para superar las limitaciones que los stents con andamio metálico provocan. En el año 2019, Park y col. desarrollan un stent polimérico biodegradable impreso mediante tecnología 3D, con un sensor de presión inalámbrico integrado, diseñado para aplicaciones avanzadas de monitoreo de la salud. En dicho estudio se fabricó un stent 
basado en policaprolactona (PCL), con un recubrimiento de fármaco similar al de los stents liberadores de fármacos, y un sensor de presión inalámbrico de poli D-lactida (PDLA) que permite la medición en tiempo real de la presión dentro del vaso sanguíneo. Sus resultados muestran que el sensor inalámbrico fabricado se une estrechamente a las paredes internas del stent debido a su alta flexibilidad, además, se absorbe completamente en el cuerpo a lo largo del tiempo. La tecnología de impresión 3D permite la fabricación de stents con una estructura de malla compleja, a diferencia de los procesos tradicionales.

Sistemas de liberación de fármacos

El uso de tratamientos convencionales para el cáncer, como la quimioterapia o la resección quirúrgica, con frecuencia ocasionan efectos secundarios no deseados en el paciente. Por tal motivo, la búsqueda de nuevos tratamientos con acción localizada ha generado gran interés entre los investigadores. Los científicos han analizado muchos métodos para mejorar el encapsulamiento y trasporte de medicamentos con el fin de mejorar el perfil de liberación.

Recientemente, se ha prestado gran atención al control de la estructura tridimensional (3D) y al diseño de diferentes formas en 3D en las dimensiones a nano y microescala de los acarreadores de fármaco. Los investigadores buscan que el control de la forma y tamaño de las partículas acarreadoras aumente la eficacia de los fármacos, especialmente los diseñados para combatir el cáncer.

En un estudio realizado en el año 2018 por Yang y col., se fabricó un implante hueco en forma de bala con una superficie porosa mediante impresión 3D. El dispositivo fue cargado con el agente quimioterapéutico citoxano (CTX), como matriz alcohol tetradecílico o lecitina y fue recubierto con ácido poliláctico (PLA). Posee un tiempo de liberación de fármaco de 4 horas a más de un mes, la liberación de fármaco del implante 
se puede controlar fácilmente cambiando el tamaño de los poros, el tipo de matriz y el espesor del recubrimiento. En dicho estudio se combinó de manera exitosa la técnica de impresión 3D y el recubrimiento para fabricar implantes intratumorales.

\subsubsection{Ingeniería de tejidos}

En la actualidad, existe un desafío importante para la medicina a nivel mundial: la escasez de donantes para trasplantes de órganos y tejidos. Los científicos han encontrado en la impresión 3D, o manufactura aditiva, la tecnología para afrontar dicho desafío, puesto que permite personalizar tejidos y órganos, además se pueden colocar arreglos celulares para promover el crecimiento celular, disminuyendo así la posibilidad de rechazo al órgano o tejido trasplantado. La combinación de la ingeniería de tejidos y la técnica de impresión 3D ha significado un gran avance para la medicina actual.

Puesto que se ha buscado corregir defectos en huesos, cartílagos y diafragma, desarrollar sustitutos de córnea y fabricar estructuras cerebrales, ya que la bioimpresión es una técnica que permite la impresión de materiales biodegradables con células en tejido 3D.

Un prerrequisito básico, y quizá el mayor desafío actual, para la supervivencia y la función de construcciones de tejidos u órganos por impresión 3D es el establecimiento de vasos sanguíneos. La bioimpresión en 3D con redes vasculares que se asemejen a estructuras in vivo permitirá la circulación sanguínea dentro de las construcciones de tejido. Miri y col. en el 2019 han presentado una interesante revisión acerca de las combinaciones de técnicas de bioimpresión en 3D y el modelado de factores proangiogénicos, en donde los autores discuten que, para mantener la formación a largo plazo de nuevos capilares, se debe tener controlados los estímulos con factores proangiogénicos.

Estructuras cerebrales 
El cerebro es un órgano enormemente complejo estructurado es varias capas de tejido, encargado de controlar y regular la mayoría de las funciones del cuerpo. Por tal motivo, desde el año 2015, Lozano y col., han buscado desarrollar un modelo in vitro del cerebro para la comprensión de su funcionamiento a nivel de órgano y tejido. En dicho estudio, se demostró un nuevo método para para realizar una bioimpresión de estructuras 3D tipo cerebro que consisten en capas de células neurales primarias encapsuladas en hidrogeles. Las estructuras se construyeron en una tinta biológica basada en un biopolímero modificado; goma gellan y RGD (RGD-GG). Se encontró que la modificación peptídica del hidrogel de goma gellan tiene un profundo efecto positivo sobre la proliferación de las células primarias neuronales, así como en la formación de redes. Estas estructuras similares al cerebro brindan la oportunidad de reproducir microestructuras 3D más precisas, con diversas aplicaciones que van desde estudios de comportamiento celular hasta la comprensión de las lesiones cerebrales y diversas enfermedades neurodegenerativas.

Tres años más tarde, en el año 2018, Ho y col. buscan también el desarrollo de estructuras cerebrales. En dicho estudio, se sintetizó un gel de poliuretano (PU) biodegradable y se coextruyó con los plásmidos FoxD3 y fibroblastos humanos. Forkhead box D3 (FoxD3) es un factor de transcripción y un marcador de la cresta neural, que reprograma los fibroblastos humanos en células similares a la cresta neural. Los resultados mostraron que los fibroblastos humanos podían reprogramarse en células similares a tallos de la cresta neural. La construcción de tejido similar al tejido neural por bioimpresión 3D de fibroblastos humanos, puede aplicarse a la detección de fármacos así como a la neurorregeneración.

\section{Diafragma}

Las hernias diafragmáticas son una gran preocupación, ya que se trata de un defecto que permite que los órganos del abdomen se desplacen a la cavidad torácica poniendo en 
riesgo la vida del paciente. Por tal razón, en el año 2018, Xiu y col. buscan dar solución a las hernias diafragmáticas de neonatos que a menudo requieren el cierre del defecto quirúrgico con un parche. La eficacia clínica de los parches existentes está limitada por el material extraño y por la recurrencia de la hernia. Por tal motivo, en el estudio de Xiu y col., utilizan un nuevo método de bioimpresión 3D para generar parches de tejido sin andamios, compuestos de células humanas. Los parches celulares basados en fibroblastos dérmicos humanos normales (NHDF, CC-2509) y células endoteliales de la vena umbilical (HUVEC, C2517A) en una solución de gelatina, se trasplantaron en ratas con defectos diafragmáticos creados quirúrgicamente. Las ratas pudieron sobrevivir durante más de 710 días después de la implantación del parche. Los resultados demuestras que los parches celulares creados mediante impresión 3D con seguros y efectivos para la reparación de los defectos diafragmáticos.

\section{Córnea}

La córnea es una parte esencial para la visión y, la ceguera corneal provocada por traumas o enfermedades afecta a millones de personas alrededor del mundo. En el año 2018, Sorkio y col., buscan fabricar un sustituto de córnea mediante impresión 3D, produciendo tejidos que simulan la córnea utilizando células madre humanas y la técnica de bioimpresión asistida por láser. Se emplearon células madre epiteliales (hESC-LESC) como fuente celular para imprimir estructuras que imitan al epitelio, mientras que para construir estructuras que imiten el estroma se utilizaron células madre derivadas del tejido adiposo (hASCs). Luego de 7 días en cultivos de órganos porcinos, las estructuras se unieron al tejido del huésped. Este estudio demuestra la viabilidad de la impresión 3D para aplicaciones corneales utilizando células madre humanas. Por otro lado, en el año 2018 Dehghani y col., desarrollan una membrana mediante impresión 3D como alternativa a la membrana amniótica, para la reconstrucción de la superficie ocular. La membrana amniótica se emplea en el área de la oftalmología para reconstruir 
y trata las lesiones de la superficie ocular, ya sea en la córnea o conjuntiva, es decir, la membrana que cubre la cámara anterior del globo ocular. El trasplante de membrana amniótica en una lesión de la superficie ocular disminuye la gravedad de la lesión y evita el trasplante de córnea. En dicho estudio, se obtuvo una membrana impresa en 3D basada en una mezcla de gelatina, hialuronato de sodio y elastina, para la reconstrucción de la conjuntiva y realizar una comparación con la membrana amniótica, que como ya mencionó, se emplea normalmente para el tratamiento de lesiones. Se evaluaron las propiedades físicas y mecánicas de las membranas impresas, así como la proliferación y adhesión in vitro de las células. De igual manera, se realizó una evaluación in vivo mediante la implantación de las membranas en defectos inducidos en conejos. Se encontró que las membranas impresas tenían características ópticas favorables, además, los niveles de inflamación fueron bajos. La membrana a base de gelatina, hialuronato de sodio y elastina, ofrece características físicas y mecánicas necesarias para la construcción exitosa de la superficie ocular y puede considerarse una alternativa prometedora para el tratamiento de lesiones en la superficie ocular.

Huesos y cartílagos

La ingeniería de tejidos y la impresión 3D también buscan dar solución a los defectos de huesos y cartílagos, puesto que dichos defectos causan con frecuencia un movimiento limitado y una función deteriorada. Por ello, Liu y col. en el año 2019, desarrollan un andamio de tres capas utilizado la impresión 3D de múltiples boquillas basada en extrusión. El andamio fue basado en un hidrogel de gelatina metacrilada (GelMA) con nanopartículas de hidroxiapatita (nHA), (GelMA/ nHA) y, fue colocado en conejos. Se evaluaron las propiedades físicas, mecánicas y biológicas del andamio y, se encontró que los andamios eran apropiados para reparar los defectos del cartílago y los tejidos óseos subcondrales. La reparación in vivo de los defectos osteocondrales dio como resultado la regeneración de los tejidos en los defectos, buena integridad con el tejido 
circundante, matriz extracelular del cartílago altamente depositada y abundante colágeno tipo II. En el mismo año Lai y col., buscan desarrollar una posible solución a un trastorno ortopédico llamado osteonecrosis, se trata de una enfermedad de los huesos que puede causar dolor o limitar la actividad física provocada por la pérdida del suministro de sangre a los huesos. Por tal motivo, en dicho estudio formulan un andamio poroso de magnesio $(\mathrm{Mg})$, polilactidacoglicolida (PLGA) y fosfato $\beta$-tricálcico ( $\beta$-TCP) mediante impresión 3D con la técnica de deposición capa por capa. La liberación de iones magnesio se analizó de forma in vitro, mientras que la bioseguridad luego de la implantación, las propiedades osteogénicas y angiogénicas, se evaluaron en un conejo. Los resultados mostraron que el andamio de Mg/PLGA/ $\beta$-TCP poseía una buena estructura física y propiedades mecánicas adecuadas, de igual manera el andamio promovió el crecimiento de nuevos vasos sanguíneos a las 4 semanas después de la implantación, mientras que a las 12 semanas mostró que podría mejorar significativamente la formación del hueso y fortalecer las propiedades mecánicas óseas recién formadas. El andamio desarrollado por Lai y col. promete ser un biomaterial competente en la reparación de defectos óseos. Chen y col. en el año 2019, buscan también lograr la regeneración de los defectos osteocondrales causados por enfermedades degenerativas. En este estudio se desarrolla con éxito un biocerámico de silicato de calcio y litio (Li2Ca4Si4O13, L2C4S4) mediante un método de impresión 3D. El soporte biológico L2C4S4 mostró una biodegradabilidad controlada y una buena capacidad de mineralización de apatita, a cierta concentración los productos iónicos del andamio L2C4S4 estimularon la proliferación y maduración de los condrocitos. Así mismo, se promovió la regeneración de cartílago y hueso subcondral. Estos resultados sugieren que el andamio desarrollado por Chen y col. representa un prometedor biomaterial para la reconstrucción de la interfaz osteocondral.

Conductos nerviosos 
Si bien se han descrito diversos estudios donde se ha desarrollado una diversidad de tejidos, órganos, prótesis e implantes mediante la tecnología de impresión 3D, la fabricación de conductos nerviosos aún parece algo lejano de lograr. Sin embargo, para Xu y col. esto fue posible, pues en el año 2019 desarrollan un conducto nervioso impreso en 3D con liberación de fármaco para promover la regeneración nerviosa. El desarrollo de conductos nerviosos promete superar los defectos de los nervios periféricos que causan discapacidad.

Se fabricó un conducto nervioso basado en gelatina metacrilada (GelMA) con nanopartículas cargadas con RGFP966 (R-NP) para promover la remielinización de las células de Schwann mediante la activación de PI13K-AKT-ERK. Este conducto nervioso presentaba una superficie interna alineada direccionalmente con fibras, personalizada con un procesamiento de luz digital (DLP) basado en impresión 3D. Este estudio demuestra la factibilidad y eficacia de las R-NP para regenerar los conductos nerviosos dañados, así como las ventajas de personalización que ofrece la tecnología de impresión 3D.

En la Tabla 1, se presenta un resumen de las aplicaciones de dispositivos médicos desarrollados mediante la técnica de impresión 3D o manufactura aditiva, se menciona también el biomaterial empleado para la impresión de implantes, prótesis y tejidos, así como la técnica de impresión utilizada.

Tabla 1 Clasificación de dispositivos médicos desarrollados mediante impresión 3D.

\begin{tabular}{|l|l|l|l|l|}
\hline CATEGORÍA & APLICACIÓN & MATERIAL & TÉCNICA DE \\
Implant & Craneales & Biomaterial para & Poliamida 12- Zirconia- $\beta-$ & Modelado por \\
es & reconstrucción & $T C P$ & deposición \\
& craneofacial & fundida (c, \\
\hline
\end{tabular}




\begin{tabular}{|c|c|c|c|}
\hline & & & $\begin{array}{l}\text { FDM por sus } \\
\text { siglas en inglés) }\end{array}$ \\
\hline Cardíacos & $\begin{array}{l}\text { Anillo aórtico basado } \\
\text { en mediciones de } \\
\text { tomografía } \\
\text { computarizada } \\
\text { cardiovascular }\end{array}$ & Poliuretano (PU) & $\begin{array}{l}\text { Modelado por } \\
\text { deposición } \\
\text { fundida (Fused } \\
\text { deposition } \\
\text { modelling, FDM } \\
\text { por sus } \\
\text { siglas en inglés) }\end{array}$ \\
\hline & $\begin{array}{l}\text { Oclusor biodegradable } \\
\text { para defectos cardíacos }\end{array}$ & PLLA-TMC-GA (PLTG) & - \\
\hline De rodilla & $\begin{array}{l}\text { Mezcla polimérica } \\
\text { para menisco artificial } \\
\text { de rodilla }\end{array}$ & $\begin{array}{l}\text { Policarbonato de uretano } \\
\text { (PCU) Polietileno de ultra } \\
\text { alto peso molecular } \\
\text { (UHMWPE) }\end{array}$ & $\begin{array}{l}\text { Modelado por } \\
\text { deposición } \\
\text { fundida (Fused } \\
\text { deposition } \\
\text { modelling, FDM } \\
\text { por sus } \\
\text { siglas en inglés) }\end{array}$ \\
\hline Dentales & $\begin{array}{l}\text { Moldes personalizados } \\
\text { para rellenos dentales }\end{array}$ & Ácido poliláctico (PLA) & $\begin{array}{l}\text { Modelado por } \\
\text { deposición } \\
\text { fundida (Fused } \\
\text { deposition } \\
\text { modelling, FDM } \\
\text { por sus } \\
\text { siglas en inglés) }\end{array}$ \\
\hline
\end{tabular}




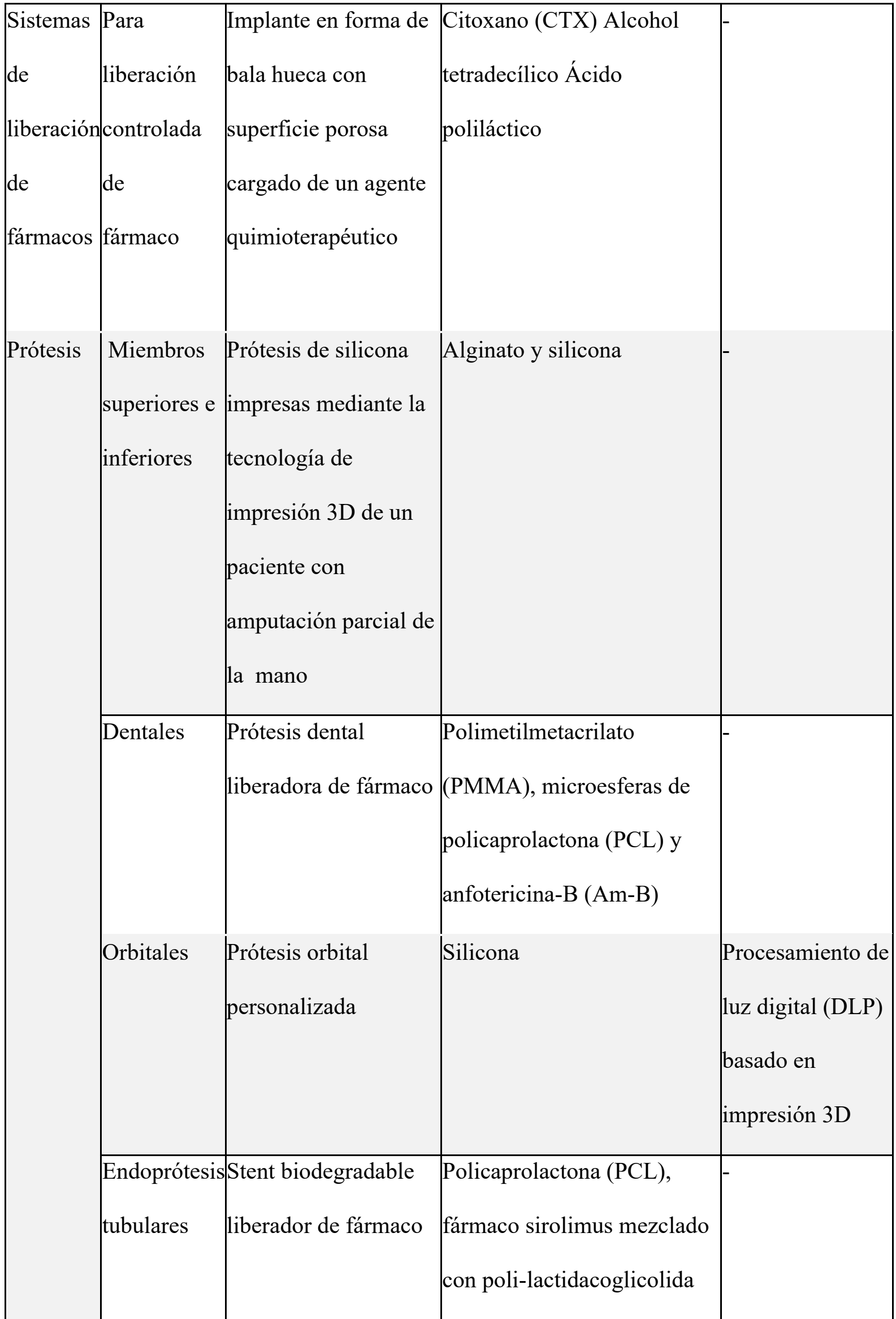




\begin{tabular}{|c|c|c|c|c|}
\hline & & & $\begin{array}{l}\text { (PLGA) y polietilenglicol } \\
(\mathrm{PEG})\end{array}$ & \\
\hline \multicolumn{2}{|c|}{ CATEGORÍA } & APLICACIÓN & MATERIAL & $\begin{array}{l}\text { TÉCNICA DE } \\
\text { IMPRESIÓN }\end{array}$ \\
\hline & & $\begin{array}{l}\text { Stent polimérico } \\
\text { biodegradable con } \\
\text { sensor de presión }\end{array}$ & $\begin{array}{l}\text { Policaprolactona (PCL) y } \\
\text { poliDlactida (PDLA) }\end{array}$ & - \\
\hline \multirow[t]{2}{*}{$\begin{array}{l}\text { Ingenier } \\
\text { ia } \\
\text { de tejidos }\end{array}$} & $\begin{array}{l}\text { Estructuras } \\
\text { cerebrales }\end{array}$ & $\begin{array}{l}\text { Estructura en forma } \\
\text { de cerebro a partir de } \\
\text { células neuronales } \\
\text { primarias } \\
\text { encapsuladas en } \\
\text { hidrogeles } \\
\text { Hidrogel para } \\
\text { fabricación de } \\
\text { estructuras tipo neural } \\
\text { a partir de fibroblastos } \\
\text { humanos }\end{array}$ & $\begin{array}{l}\text { Solución RGD-GG } \\
\text { combinada con neurona } \\
\text { cortical primaria }\end{array}$ & $\begin{array}{l}\text { Proceso de } \\
\text { impresión simple } \\
\text { utilizando dos } \\
\text { reticuladores } \\
\text { iónicos } \\
\text { Extrusión }\end{array}$ \\
\hline & Diafragma & $\begin{array}{l}\text { Parche para } \\
\text { regeneración de } \\
\text { diafragma }\end{array}$ & $\begin{array}{l}\text { Fibroblastos dérmicos } \\
\text { humanos normales (NHDF, } \\
\text { CC-2509), células } \\
\text { endoteliales de la vena } \\
\text { umbilical }\end{array}$ & Método Kenzan \\
\hline
\end{tabular}




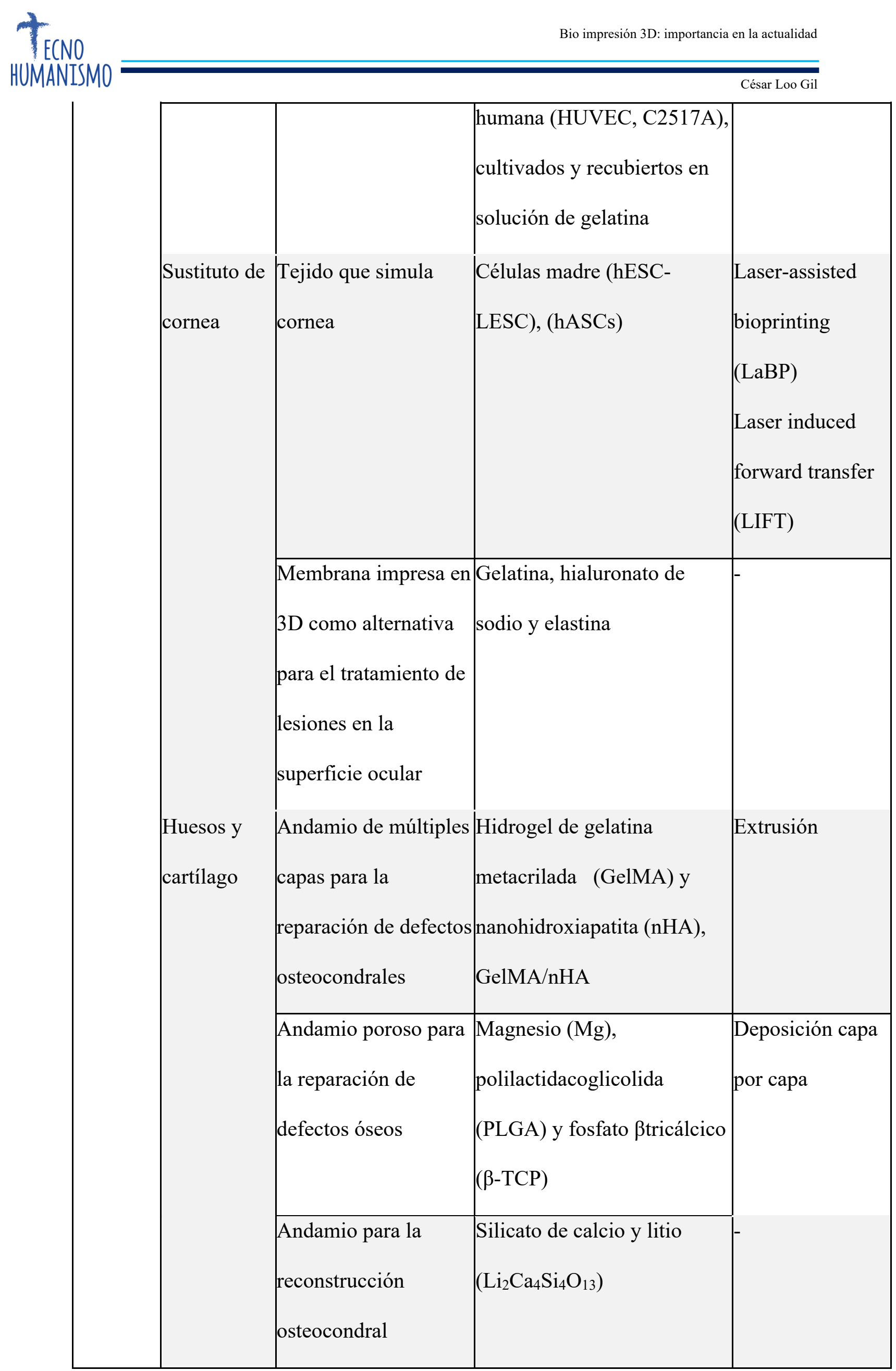




\begin{tabular}{|l|l|l|l|}
\hline Conductos & Conducto nervioso & Gelatina metacrilada & Procesamiento de \\
nerviosos & impreso en 3D con & (GelMA) con nanopartículas & luz digital (DLP) \\
& liberación de & cargadas con RGFP966 (R- & basado en \\
& fármaco para & NP) & impresión 3D \\
& promover la & & \\
\hline
\end{tabular}

Nota: (-) Técnica de impresión no especificada.

\subsubsection{Limitaciones de la impresión 3D}

Esencialmente se comentan 3 limitantes en la impresión 3D: las dimensiones del objeto a imprimir, el tiempo y los costo. La impresión 3D sólo puede aplicarse a estructuras que no excedan ciertas di- mensiones ya que las impresoras no son capaces de producir modelos extremadamente grandes, como el cuerpo entero. La limitación se supera actualmente al producir una versión en miniatura de una estructura grande mediante posprocesado o dividiendo el modelo completo en partes más pequeñas que se pueden combinar después de la impresión.

Una limitación importante son el tiempo y el costo que se invierte en la generación de objetos 3D. En la actualidad, el uso generalizado de prototipos rápidos para la planificación quirúrgica o el diseño de implantes individuales no parece justi- ficarse porque los procedimientos de planificación estándar o los implantes estándar son suficientes. Sin embargo, en los casos complicados, los costos adicionales pueden compensarse por los tiempos operativos reducidos y una mayor tasa de éxito del procedimiento quirúrgico.

El tiempo necesario para producir un objeto 3D también limita su uso en cirugía a casos electivos y lo hace inadecuado para situaciones de emergencia.

\section{LA BIOIMPRESIÓN 3D: UN PASO HACIA EL FUTURO, MÁS ALLÁ DE LA} IMPRESIÓN 3D, DE LA MANO DE LA MEDICINA REGENERATIVA 
La medicina regenerativa (término introducido a la MeSH en 2004) se define como "el campo de la medicina relacionado con el desarrollo y uso de estrategias dirigidas que tienen como objetivo la reparación o reemplazo de órganos, tejidos y células dañados, enfermos o metabólicamente deficientes a través de la ingeniería de tejidos, trasplante de células, u órganos artificiales o bioartificiales y tejidos".

Para lograr este objetivo, los andamios biomédicos hechos de polímeros naturales o sintéticos se han utilizado habitualmente en aplicaciones biomédicas y de ingeniería de tejidos para reemplazar o regenerar los tejidos nativos funcional y estructuralmente. En general, estos andamios deben cumplir con varias funciones obligatorias como proporcionar vías internas para la unión celular y la migración (poros), transferir varios factores de crecimiento y productos de desecho, y mantener su forma, mientras las células continúan creciendo y desarrollando propiedades mecánicas adecuadas o compatibles.

El desarrollo de sistemas libres de disolventes, a base de agua, ha permitido la impresión directa de materiales biológicos en andamios 3D que podrían utilizarse para el trasplante con o sin células sembradas. Por lo tanto, la tecnología de bioim- presión 3D es uno de los métodos más apropiados para producir andamios para cultivos celulares, se logra así ensamblar material biológico o células en una organización prescrita para crear estructuras funcionales tales como microarreglos celulares o estructuras anatómicas tridimensionales (MeSH 2013) lo que permite que se mantengan dentro de la estructura 3D, su fisiología y viabilidad. Los avan- ces introducidos por esta técnica han aumentado considerablemente la capacidad de controlar la distribución del tamaño del poro, su volumen y la interconectividad de los poros en los andamios. Algunos procesos de impresión en 3D se realizaron en hidrogeles como andamios y se obtuvieron con éxito estructuras 3D a temperatura ambiente sin ningún efecto significativo en la viabilidad celular. 
La impresión 3D capa por capa consiste en dar un posicionamiento preciso de materiales biológicos, bioquímicos y células vivas, con el control espacial de la colocación de estos componentes funcionales puede obtenerse una copia fiel del tejido original.

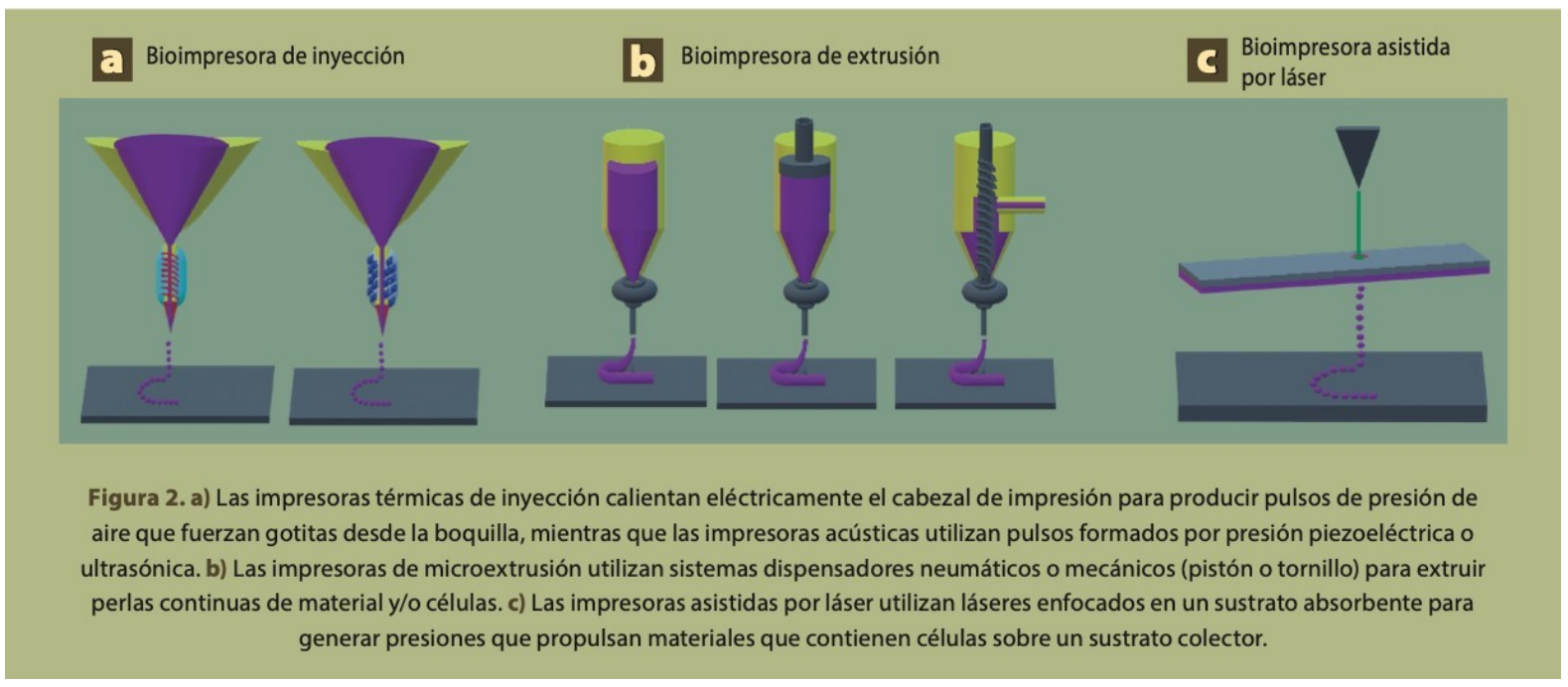

Existen algunos enfoques para la bioimpresión 3D como el biomimetismo (imitación anatomofuncional de un tejido), el autoensamblaje autónomo y los minitejidos (en bloques de construcción). El fin común de todos ellos es generar un tejido con propiedades biológicas y mecánicas adecuadas para la restauración clínica del tejido y la función de los órganos.

El reto principal en la impresión 3D es convertirla a una bioimpresión, en la que sea posible reproducir la compleja microarquitectura de los componentes de la matriz extracelular (MEC) y los diferentes tipos de células con la resolución suficiente para recapturar la función biológica.

Los materiales actualmente utilizados en el cam- po de la medicina regenerativa para la reparación y regeneración se basan principalmente en el em- pleo de polímeros de origen natural (incluyendo alginato, gelatina, colágeno, quitosano, fibrina y ácido hialurónico, a menudo aislados de tejidos ani- males o humanos) o moléculas sintéticas 
como el polietilenglicol (PEG). Las ventajas de los polímeros naturales para

bioimpresión y otras aplicaciones de ingeniería de tejidos son su similitud con la MEC (matriz extracelular) humana y su bioactividad inherente. La ventaja de los polímeros sintéticos con propiedades físicas específicas es que pueden adaptarse para aplicaciones particulares. Los desafíos en el uso de polímeros sintéticos incluyen una baja biocompatibilidad, productos de degradación tóxica y pérdida de propiedades mecánicas durante la degradación. Aun así, los hidrogeles sintéticos, que son a la vez hidrófilos y absorbentes, son atractivos para múltiples aplicaciones en la medicina regenerativa debido a la facilidad de controlar sus propiedades físicas durante la fabricación. A medida que los tejidos bioimpresos se desarro- llan in vivo, deben ser susceptibles de remodelación, facilitando la formación de estructuras moduladas por los requerimientos celulares y fisiológicos. Lo más importante es que los materiales deben apoyar el apego, la proliferación y la función celular.

Las principales tecnologías utilizadas para deposi- tar y modelar materiales biológicos son: la inyección, la microextrusión y la impresión asistida por láser (figura 2). Deben considerarse las diferentes caracte- rísticas de éstas, que son de manera general la resolu- ción superficial, la viabilidad celular y los materiales biológicos utilizados para la 


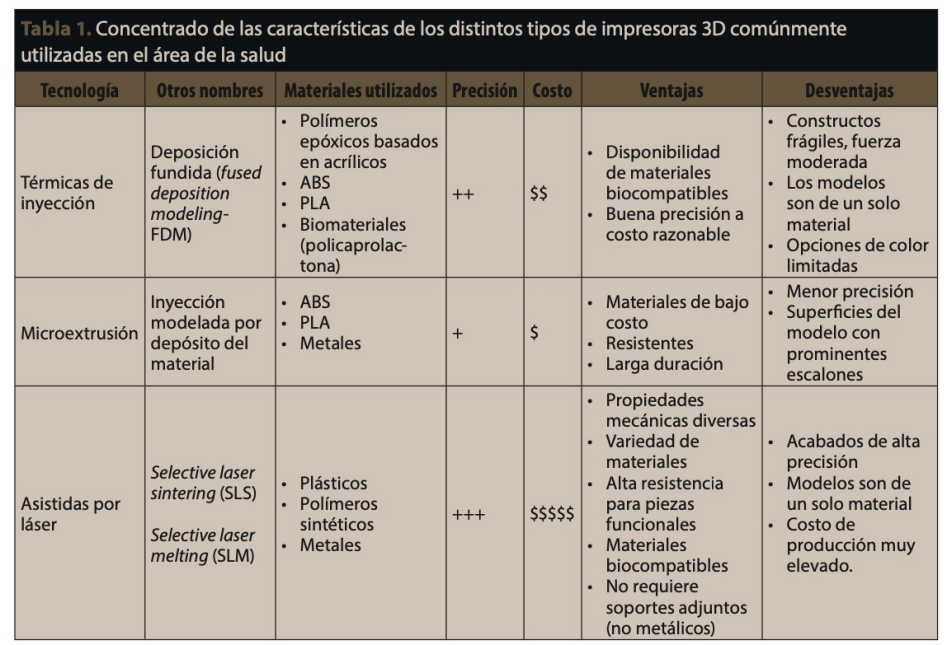

impresión, así como sus ventajas y desventajas en general (tabla 1).

La elección de células para la impresión de te jidos u órganos, es crucial para el correcto funcionamiento de la impresión. Los tejidos y los órganos comprenden múltiples tipos de células con funciones biológicas específicas y esenciales que deben retomarse en el tejido trasplantado. Además de los tipos de células funcionales primarias, la mayoría de los tejidos también tienen tipos de células que proporcionan funciones de soporte, estructurales o de barrera, participan en la vascularización o pro- porcionan un nicho para el mantenimiento y la diferenciación de las células madre. Las opciones actuales para imprimir células implican el depósito de múltiples tipos de células primarias en patrones que representan fielmente el tejido nativo o que imprimen células madre que pueden proliferar y diferenciarse en los tipos de células requeridos.

La célula elegida para impresión debe ser capaz de expandirse en números suficientes en dicha im-presión. El control preciso de la proliferación celular in vitro e in vivo es importante para la bioimpresión. La escasa proliferación puede dar lugar a la pérdida de viabilidad del impreso trasplantado, mientras que demasiada proliferación puede dar lugar a hiperplasia o apoptosis. Además, el momento de la proliferación celular es importante. Inicialmente, puede ser deseable una alta tasa de proliferación celular para poblar la construcción, pero a largo plazo, la proliferación debe mantenerse a una velo- 
cidad adecuada para lograr la homeostasis tisular, aunque sin hiperplasia. Se ha intentado resolver este problema mediante la transfección viral o el uso de moléculas pequeñas para inducir la proliferación celular y prevenir la senescencia.

Al igual que con cualquier tejido u órgano tras- plantado, el rechazo del implante impreso por el sistema inmune del receptor es un problema po- tencial que puede ser superado usando una fuente autóloga de células o estrategias de la tolerancia inducción. Las fuentes autólogas de células pueden obtenerse a partir de biopsias, desde la generación y diferenciación de células madre autólogas o mediante reprogramación.

\section{CONCLUSIONES}

El desarrollo de dispositivos médicos mediante el método de impresión 3D ha logrado un progreso significativo, pues se han fabricado diversos modelos de prótesis, implantes y tejidos combinando el uso de diferentes técnicas de manufactura aditiva con la incorporación de arreglos celulares, promoviendo la regeneración de estructuras biológicas.

Se han empleado técnicas médicas ya establecidas, como la tomografía computarizada en la impresión 3D, obteniendo una concordancia idónea en el modelo tridimensional y la anatomía del paciente. Los biomateriales empleados en la impresión 3D, consisten en compuestos poliméricos y cerámicas biodegradables, logrando propiedades físicas y mecánicas idóneas. Un desafío importante en el desarrollo de dispositivos médicos mediante impresión 3D, es la incorporación de equipos de manufactura aditiva en hospitales, por esta razón, es previsible que la investigación básica y aplicada se intensifiquen en los próximos años y haya más estudios clínicos para tener productos disponibles comercialmente.

La importancia de la aplicación de las TFA en medi- cina radica en permitir la reproducción de un tejido u órgano mediante el uso de la bioimpresión, con lo que se espera un impacto trascendente en múltiples especialidades médicas (cirugía plástica 
reconstructi- va, cirugía maxilofacial, ortopedia, cirugía de colum- na, artroscopía, cirugía de trasplantes, entre muchas otras). La expectativa en Latinoamérica de estas tec- nologías es que sean un campo emergente en benefi- cio de los pacientes con la generación de implantes u órganos personalizados que favorezcan el pronóstico y la evolución de los tratamientos otorgados.

\section{CONCLUSIONES}

Abdullah AM, Tuan Rahim TNA, Mohamad D, Akil HM, Rajion ZA. Mechanical and physical properties of highly $\mathrm{ZrO} 2 / \beta$-TCP filled polyamide 12 prepared via fused deposition modelling (FDM) 3D printer for potential craniofacial reconstruction application. Mater Lett [Internet]. 2017;189:307-9. Available from: http://dx.doi. org/10.1016/j.matlet.2016.11.052

Almeida HA, Costa AF, Ramos C, Torres C, Minondo M, Bártolo PJ, et al. Additive Manufacturing Systems for Medical Applications: Case Studies. In: Additive Manufacturing - Developments in Training and Education [Internet]. Cham: Springer International Publishing; 2019 [cited 2019 Jul 5]. p. 187-209. Available from: http://link.springer.com/10.1007/978-3-319-76084-1_13

Alvial P, Bravo G, Bustos MP, Moreno G, Alfaro R, Cancino R, et al. Quantitative functional evaluation of a 3D-printed silicone-embedded prosthesis for partial hand amputation:

A case report. J Hand Ther [Internet]. 2018;31(1):129-36. Available from: https://doi.org/10.1016/j.jht.2017.10.001

Araujo Borges R, Choudhury D, Zou M. 3D printed PCU/UHMWPE polymeric blend for artificial knee meniscus. Tribol Int [Internet]. 2018;122(January):1-7. Available from: https://doi.org/10.1016/j.triboint.2018.01.065

Ashammakhi N, Ahadian S, Xu C, Montazerian H, Ko H, Nasiri R, et al. Bioinks and bioprinting technologies to make heterogeneous and biomimetic tissue constructs. 
Mater Today Bio [Internet]. 2019 Jan 1 [cited 2019 Jul 4];1:100008. Available from:

https://www.sciencedirect.com/science/article/pii/S2590006419300146

Carrow JK, Kerativitayanan P, Jaiswal MK, Lokhande G, Gaharwar AK. Polymers for Bioprinting. Essentials 3D Biofabrication Trans1 [Internet]. 2015 Jan 1 [cited 2019 Jul 4];229-48. Available from:

https://www.sciencedirect.com/science/article/pii/B978012800972700013X

Chen L, Deng C, Li J, Yao Q, Chang J, Wang L, et al. 3D printing of a

lithiumcalciumsilicate crystal bioscaffold with dual bioactivities for osteochondral interface reconstruction. Biomaterials [Internet]. 2019 Mar [cited 2019 Jun 27];196:13850. Available from: https://linkinghub.elsevier.com/retrieve/pii/S0142961218302448

Chia HN, Wu BM. Recent advances in 3D printing of biomaterials. J Biol Eng [Internet].

2015 Dec 1 [cited 2019 Jul 4];9(1):4. Available from:

http://www.jbioleng.org/content/9/1/4 Coburn JC, Grant GT. FDA Regulatory Pathways and Technical Considerations for the 3D Printing of Medical Models and Devices. In: 3D Printing in Medicine [Internet].

Cham: Springer International Publishing; 2017 [cited 2019 Jul 5]. p. 97-111. Available from: http://link.springer.com/10.1007/978-3-319-61924-8_10

Colombo G, Rizzi C, Regazzoni D, Vitali A. 3D interactive environment for the design of medical devices. Int J Interact Des Manuf [Internet]. 2018 May 29 [cited 2019 Jul 4];12(2):699-715. Available from: http://link.springer.com/10.1007/s12008-01804588

D’Urso P, Earwaker W, Barker T, Redmond M, Thomp- son R, Effeney D, Tomlinson F Custom cranioplasty us- ing stereolithography and acrylic. Br J Plast Surg. 2000; 53:200-204. 
Dehghani S, Rasoulianboroujeni M, Ghasemi H. Biomaterials 3D-Printed membrane as an alternative to amniotic membrane for ocular surface / conjunctival defect reconstruction : An in vitro \& in vivo study. $2018 ; 174$

Di Prima M, Coburn J, Hwang D, Kelly J, Khairuzzaman A, Ricles L. Additively manufactured medical products - the FDA perspective. 3D Print Med [Internet]. 2016 Dec 1 [cited 2019 Jul 5];2(1):1. Available from: https://threedmedprint.biomedcentral.com/articles/10.1186/s41205-016-0005-9 [ Links ] Elgalal M, Kozakiewicz M, Olszycki M, Walkowiak B, Stefanczyk L Custom implant design and surgical pre-plan- ning using rapid prototyping and anatomical models for the repair of orbital floor fractures. Eur Radiol. 2009; 19(Suppl 1):S397.

Faber J, Berto P, Quaresma M. Rapid prototyping as a tool for diagnosis and treatment planning for maxillary canine impaction. Am J Orthod Dentofacial Orthop. 2006; 129:583-589.

Faletti R, Gatti M, Cosentino A, Bergamasco L, Cura Stura E, Garabello D, et al. 3D printing of the aortic annulus based on cardiovascular computed tomography:

Preliminary experience in pre-procedural planning for aortic valve sizing. J Cardiovasc Comput

Tomogr [Internet]. 2018;12(5):391-7. Available from:

https://doi.org/10.1016/j.jcct.2018.05.016

Farooqi KM, Cooper C, Chelliah A, Saeed O, Chai PJ, Jambawalikar SR, et al. 3D

Printing and Heart Failure: The Present and the Future. JACC Hear Fail [Internet]. 2019 Feb 1

[cited 2019 Jul 5];7(2):132-42. Available from:

https://www.sciencedirect.com/science/article/pii/S2213177918307169

Galante R, Figueiredo-Pina CG, Serro AP. Additive manufacturing of ceramics for dental applications: A review. Dent Mater [Internet]. 2019 Jun 1 [cited 2019 Jul 
5];35(6):825-46. Available from:

https://www.sciencedirect.com/science/article/pii/S0109564118304263

García-Valadez L, Espinoza-Gutiérrez A, Rivas-Montero J, Hernández-Méndez V,

Santiago- García A, Banegas- Ruiz R, Cesar-Juárez A, Palmieri-Bouchan R. Impresión de modelos 3D para fracturas de radio distal: un estudio piloto en el Instituto Nacional de Rehabilitación. Rev Sanid Milit Mex. 2017;71:366-73.

Gibson I, Rosen DW, Stucker B. Medical Applications for Additive Manufacture. In: Additive Manufacturing Technologies [Internet]. Boston, MA: Springer US; 2010 [cited 2019 Jul 5]. p. 400-14. Available from: http://link.springer.com/10.1007/97814419-1120-9_15

Gopinathan J, Noh I. Recent trends in bioinks for 3D printing. Biomater Res [Internet]. 2018 Dec 6 [cited 2019 Jul 4];22(1):11. Available from: https://biomaterialsres.biomedcentral.com/articles/10.1186/s40824-018-0122-1 Ho L, Hsu S hui. Cell reprogramming by 3D bioprinting of human fibroblasts in polyurethane hydrogel for fabrication of neural-like constructs. Acta Biomater [Internet]. 2018;70:57-70. Available from: https://doi.org/10.1016/j.actbio.2018.01.044 Javaid M, Haleem A. Additive manufacturing applications in orthopaedics: A review. J Clin Orthop Trauma [Internet]. 2018 Jul 1 [cited 2019 Jul 5];9(3):202-6. Available from:

https://www.sciencedirect.com/science/article/pii/S097656621830122X

Kim SH, Shin WB, Baek SW, Yoon JS. Semiautomated fabrication of a custom orbital prosthesis with 3-dimensional printing technology. J Prosthet Dent [Internet]. 2019;14. Available from: https://doi.org/10.1016/j.prosdent.2019.03.021

Lai Y, Li Y, Cao H, Long J, Wang X, Li L, et al. Osteogenic magnesium incorporated into PLGA/TCP porous scaffold by 3D printing for repairing challenging bone defect. Biomaterials. 2019;197(September 2018):207-19. [ Links ] 
Lal H, Patralekh MK. 3D printing and its applications in orthopaedic trauma: A technological marvel. J Clin Orthop Trauma [Internet]. 2018 Jul 1 [cited 2019 Jul 5];9(3):260-8. Available

from: https://www.sciencedirect.com/science/article/pii/S0976566218303850

Lantada AD, Morgado PL, Stampfl J. Additive Manufacturing Technologies for Enhancing the Development Process of Biodevices. In: Handbook on Advanced Design and Manufacturing Technologies for Biomedical Devices [Internet]. Boston, MA: Springer US; 2013 [cited 2019 Jul 5]. p. 181-205. Available from: http://link.springer.com/10.1007/978-1-4614-6789-2_10

Lee S-J, Zhu W, Castro N, Zhang LG. Biomaterials and 3D Printing Techniques for Neural Tissue Regeneration. In: Neural Engineering [Internet]. Cham: Springer International Publishing; 2016 [cited 2019 Jul 5]. p. 1-24. Available from: http://link.springer./10.1007/978-3-319-31433-4_1

Liu J, Li L, Suo H, Yan M, Yin J, Fu J. 3D printing of biomimetic multi-layered GelMA/nHA scaffold for osteochondral defect repair. Mater Des [Internet]. 2019;171:107708. Available from: https://doi.org/10.1016/j.matdes.2019.107708

Liu J, Sun L, Xu W, Wang Q, Yu S, Sun J. Current advances and future perspectives of 3D printing natural-derived biopolymers. Carbohydr Polym [Internet]. 2019 Mar 1

[cited

2019 Jul 4];207:297- 316. Available

from:https://www.sciencedirect.com/science/article/pii/S0144861718314103

Lozano R, Stevens L, Thompson BC, Gilmore KJ, Gorkin R, Stewart EM, et al. 3D printing of layered brain-like structures using peptide modified gellan gum substrates. Biomaterials [Internet]. 2015;67:264-73. Available from: http://dx.doi.org/10.1016/j.biomaterials.2015.07.022 
Maroulakos M, Kamperos G, Tayebi L, Halazonetis D, Ren Y. Applications of 3D

printing on craniofacial bone repair: A systematic review. J Dent [Internet]. 2019 Jan 1

[cited

2019 Jul 5];80:1-14. Available

from:https://www.sciencedirect.com/science/article/pii/S0300571218306407

Martins JP, Ferreira MPA, Ezazi NZ, Hirvonen JT, Santos HA, Thrivikraman G, et al.

3D printing: prospects and challenges. Nanotechnologies Prev Regen Med [Internet].

2018 Jan 1 [cited 2019 Jul 4];299-379. Available from:

https://www.sciencedirect.com/science/article/pii/B9780323480635000046

Mavili M, Canter H, Saglam-Aydinatay B, Kamaci S, Kocadereli I. Use of three-

dimensional medical modeling methods for precise planning of orthognathic surgery. $\mathrm{J}$

Craniofac Surg. 2007;18:740.

Mikolajczyk T, Malinowski T, Moldovan L, Fuwen H, Paczkowski T, Ciobanu I. CAD

CAM System for Manufacturing Innovative Hybrid Design Using 3D Printing. Procedia Manuf [Internet]. 2019;32:22-8. Available from:

https://doi.org/10.1016/j.promfg.2019.02.78

Miri AK, Khalilpour A, Cecen B, Maharjan S, Shin SR, Khademhosseini A. Multiscale bioprinting of vascularized models. Biomaterials [Internet]. 2019 Apr 1 [cited 2019 Jul 4];198:204-16. Available

from:https://www.sciencedirect.com/science/article/pii/S014296121830560X

Mironov V, Trusk T, Kasyanov V, Little S, Swaja R, Mark- wald R. Biofabrication: A 21st century manufacturing paradigm. Biofabrication. 2009;1:022001.

Nagrath M, Sikora A, Graca J, Chinnici JL, Rahman SU, Reddy SG, et al.

Functionalized prosthetic interfaces using 3D printing: Generating infectionneutralizing prosthesis in dentistry. Mater Today Commun [Internet]. 
2018;15(January):114-9. Available from:

https://doi.org/10.1016/j.mtcomm.2018.02.016

Park J, Kim JK, Park SA, Lee DW. Biodegradable polymer material based smart stent:

Wireless pressure sensor and 3D printed stent. Microelectron Eng [Internet].

2019;206(October 2018):1-5. Available from:

https://doi.org/10.1016/j.mee.2018.12.007

Park J, Kim JK, Park SA, Lee DW. Biodegradable polymer material based smart stent: Wireless pressure sensor and 3D printed stent. Microelectron Eng. 2019;206(October 2018):1-5

Park SA, Lee SJ, Lim KS, Bae IH, Lee JH, Kim WD, et al. In vivo evaluation and characterization of a bio-absorbable drug-coated stent fabricated using a 3D-printing system. Mater Lett [Internet]. 2015 Feb [cited 2019 Jun 25];141:355-8. Available from: https://linkinghub.elsevier.com/retrieve/pii/S0167577X14021223

Poologasundarampillai G, Nommeots-Nomm A. Materials for 3D printing in medicine: Metals, polymers, ceramics, hydrogels. 3D Print Med [Internet]. 2017 Jan 1 [cited 2019 Jul 4];43-71. Available from:https://www.sciencedirect.com/science/article/pii/B9780081007174000028 PubMed-MeSH Major Topic. “Printing, Three-Dimension- al”. [Consultado: 25agosto2017]. Disponible en: https://

www.ncbi.nlm.nih.gov/mesh/?term=Printing\%2C+Three- Dimensional

Seol YJ, Kang TY, Cho DW. Solid freeform fabrication technology applied to tissue engineering with various biomaterials. Soft Matter. 2012;8:1730-5.

Sorkio A, Koch L, Koivusalo L, Deiwick A, Miettinen S, Chichkov B, et al. Human stem cell based corneal tissue mimicking structures using laser-assisted 3D bioprinting and functional bioinks. Biomaterials [Internet]. 2018;171:57-71. Available from: https://doi.org/10.1016/j.biomaterials.2018.04.034 
Sun Y, Zhang X, Li W, Di Y, Xing Q, Cao Q. 3D printing and biocompatibility study of a new biodegradable occluder for cardiac defect. J Cardiol [Internet]. 2019;74(2):182-8. Available from: https://doi.org/10.1016/j.jjcc.2019.02.002

Takagishi K, Umezu S. Development of the improving process for the 3D printed structure.

Sci. Rep.-UK. 2017; 7:39852.

Tam CHA, Chan YC, Law Y, Cheng SWK. The Role of Three-Dimensional Printing in Contemporary Vascular and Endovascular Surgery: A Systematic Review. Ann Vasc Surg [Internet]. 2018 Nov 1 [cited 2019 Jul 5];53:243-54. Available from: https://www.sciencedirect.com/science/article/abs/pii/S089050961830503X Vaishya R, Patralekh MK, Vaish A, Agarwal AK, Vijay V. Publication trends and knowledge mapping in 3D printing in orthopaedics. J Clin Orthop Trauma [Internet]. 2018 Jul 1

[cited 2019 Jul 5];9(3):194-201. Available from: https://www.sciencedirect.com/science/article/pii/S0976566218302790 Xu X, Tao J, Wang S, Yang L, Zhang J, Zhang J, et al. 3D printing of nerve conduits with nanoparticle-encapsulated RGFP966. Appl Mater Today [Internet]. 2019;16:24756. Available from: https://linkinghub.elsevier.com/retrieve/pii/S235294071930112X Yang N, Chen H, Han H, Shen Y, Gu S, He Y, et al. 3D printing and coating to fabricate a hollow bullet-shaped implant with porous surface for controlled cytoxan release. Int $\mathbf{J}$

Pharm [Internet]. 2018;552(1-2):91-8. Available from: https://doi.org/10.1016/j.ijpharm.2018.09.042

Yang Y, Li H, Xu Y, Dong Y, Shan W, Shen J. Fabrication and evaluation of dental fillers using customized molds via 3D printing technology. Int J Pharm [Internet]. 
2019;562(December 2018):66- 75. Available from:

https://doi.org/10.1016/j.ijpharm.2019.03.024

Zhang XY, Yanagi Y, Sheng Z, Nagata K, Nakayama K, Taguchi T. Regeneration of diaphragm with bio-3D cellular patch. Biomaterials [Internet]. 2018;167:1-14.

Available from: https://doi.org/10.1016/j.biomaterials.2018.03.012 